\title{
EFEITO DO ALUMÍNIO SOBRE A ABSORÇÃO, O ACÚMULO E O FRACIONAMENTO DO FÓSFORO EM SORGO $\left({ }^{1}\right)$
}

\author{
JAMIL MORAIS PEREIRA $\left({ }^{2}\right)$; JOSÉ CAMBRAIA $\left({ }^{2 *}, 3\right)$; ÉLCIO MEIRA DA FONSECA JÚNIOR $\left({ }^{2}\right)$; \\ CLEBERSON RIBEIRO $\left({ }^{2}\right)$
}

\begin{abstract}
RESUMO
O trabalho teve como objetivo estudar o efeito do Al sobre a absorção, o acúmulo e o fracionamento do $\mathrm{P}$ em duas cultivares de sorgo. As plantas foram expostas a níveis tóxicos de Al durante dez dias e, então, colhidas e determinados o crescimento em tamanho e produção de massa seca, os teores de Al e de $\mathrm{P}$ total e as diversas formas de $\mathrm{P}$ nas duas partes das plantas. Avaliou-se, também, o efeito do Al sobre a absorção de $\mathrm{P}$ pelas raízes de plantas intactas. O Al reduziu o crescimento da raiz seminal e a produção de matéria seca de raízes e parte aérea nas duas cultivares, especialmente na sensível. Os teores de $\mathrm{Al}$ e de $\mathrm{P}$ total aumentaram nas raízes, mas não foram modificados na parte aérea nas duas cultivares. $\mathrm{A}$ absorção de $\mathrm{P}$, entretanto, decresceu na presença de $\mathrm{Al}$ nas duas cultivares, principalmente na sensível. $\mathrm{O} \mathrm{Al}$, de modo geral, modificou as concentrações das várias formas de $\mathrm{P}$ solúvel $\left(\mathrm{P}_{\mathrm{i}}\right.$ e $\left.\mathrm{P}_{\mathrm{org}}\right)$ e insolúvel $\left(\mathrm{P}_{\mathrm{RNA}}\right.$ e $\left.\mathrm{P}_{\text {residual }}\right)$, exceto a da forma $\mathrm{P}_{\text {LIP. }}$. Algumas dessas modificações parecem ser importantes e podem estar relacionadas com o mecanismo de tolerância ao Al em sorgo.
\end{abstract}

Palavras-chave: tolerância ao Al, Sorghum bicolor, fosfato inorgânico, fosfato orgânico.

\section{ABSTRACT \\ ALUMINUM EFFECT ON UPTAKE, ACCUMULATION AND FRACTIONATION OF PHOSPHORUS IN SORGHUM}

The objective of this work was to evaluate Al effect on uptake, accumulation and fractionation of $\mathrm{P}$ in two sorghum cultivars. Plants were treated with toxic levels of Al during ten days and then they were harvested and growth, dry matter yield, $\mathrm{Al}$ and total $\mathrm{P}$ contents and concentrations of the various $\mathrm{P}$ forms in the two parts of the plants were determined. Aluminum effect on P uptake was also evaluated in intact plants. Aluminum reduced the growth of the seminal root and dry matter yield in roots and tops of both cultivars, especially in the sensitive one. Aluminum and P contents increased in roots but did not change in the top of both cultivars. Phosphate uptake by roots, however, decreased in the presence of $\mathrm{Al}$ in both cultivars, especially in the sensitive one. Aluminum, in general, changed concentrations of all soluble $\left(\mathrm{P}_{\mathrm{i}}\right.$ e $\left.\mathrm{P}_{\text {org }}\right)$ and insoluble $\mathrm{P}$ forms $\left(\mathrm{P}_{\mathrm{RNA}}\right.$ e $\left.\mathrm{P}_{\text {residual }}\right)$, except of the $\mathrm{P}_{\text {LIP }}$ form. Some of these modifications seem to be important and may be related to Al tolerance mechanism in sorghum.

Key words: aluminum tolerance, Sorghum bicolor, inorganic phosphate, organic phosphate.

$\left({ }^{1}\right)$ Recebido para publicação em 24 de outubro de 2007 e aceito em 16 de junho de 2008.

$\left({ }^{2}\right)$ Departamento de Biologia Geral, CCBS, Universidade Federal de Viçosa, 36570-000 Viçosa (MG). E-mail: cambraia@ufv.br ${ }^{*}$ ) Autor correspondente.

$\left({ }^{3}\right)$ Bolsista do CNPq. 


\section{INTRODUÇÃO}

A toxidez do $\mathrm{Al}$ em plantas é considerada um dos principais fatores que limitam a produtividade das plantas em solos ácidos, que compreendem cerca de $50 \%$ de toda área potencialmente arável do mundo (Kochian et al., 2004). O Brasil possui aproximadamente 1,8 milhões de $\mathrm{km}^{2}$ de solos sob vegetação de cerrado, que se caracterizam por possuir elevada acidez, deficiência de $\mathrm{P}, \mathrm{Ca}, \mathrm{Mg}$ e teores elevados de Al e Mn (Olmos e CAmARgo, 1976).

$\mathrm{O} \mathrm{Al}$ ao ser absorvido pelas plantas tende a acumular-se preferencialmente no ápice radicular, promovendo a inibição do alongamento da raiz e a divisão celular (Kochian et al., 2004). Nos tecidos radiculares, o Al liga-se à parede celular e, ou à membrana plasmática modificando a absorção de água e macronutrientes (MendonçA et al., 2003). Uma vez no citoplasma, liga-se a numerosas macromoléculas como ácidos nucléicos e nucleotídeos fosforilados e a estruturas como o citoesqueleto, com distúrbios generalizados no metabolismo vegetal, resultando em inibição do crescimento das raízes (Kochian et al., 2004; Vitorello et al., 2005).

Em plantas submetidas a níveis tóxicos de $\mathrm{Al}$, constatam-se quase sempre, sintomas de deficiência de $P$, indicativos de interações entre estes dois elementos, que ocorrem no solo e continuam na superfície e no interior das células das raízes (GAUME et al., 2001). Na parede celular, a interação entre $\mathrm{Al}$ e $P$ resulta na formação de complexos e, principalmente, de compostos pouco solúveis como o $\mathrm{Al}_{4}\left(\mathrm{PO}_{4}\right)_{3}$, reduzindo a absorção do Al (ZHENG et al., 2005). O aumento na concentração de $P$ na solução nutritiva resultou em aumento nos teores de $\mathrm{P}$ e de $\mathrm{Al}$ nas raízes e redução diferencial do efeito do $\mathrm{Al}$ sobre o crescimento de duas cultivares de milho (GAUME et al., 2001). Resultados como estes têm levado alguns autores a postularem um possível papel do fósforo no mecanismo de tolerância ao $\mathrm{Al}$ em trigo-mouro (ZHENG et al., 2005) e milho (GAume et al., 2001). Essa imobilização, contudo, parece ser apenas parcial porque o $\mathrm{Al}$ não apenas entra no citoplasma, mas pode chegar até ao núcleo onde reage com DNA, impedindo sua replicação (Morimura e Matsumoto, 1978). No citoplasma, Al reage com praticamente todas as moléculas que possuem grupos fosfóricos na sua estrutura, resultando na elevação nas concentrações totais de Pi, ATP e nucleotídeos trifosfatados (ClARKSON, 1966). A concentração metabolicamente disponível destes e de outros intermediários fosforilados decresce e o efeito inibitório sobre certas enzimas como a hexocinase, resulta em decréscimo da taxa de fosforilação de açúcares (CLARKSON, 1966; RORISON, 1965).
As interações Al-P que ocorrem nas células, entretanto, são ainda pouco conhecidas e, infelizmente, pouco se tem feito (LiaO et al., 2006). O metabolismo do P é extremamente complexo envolvendo dezenas de moléculas e rotas metabólicas, em diferentes compartimentos celulares. No $\mathrm{pH}$ fisiológico, entre 7,0 e 7,6, a possibilidade de reação do Al com fosfato e compostos fosforilados aumenta enormemente, mesmo se as concentrações de ambos forem relativamente baixas. $\mathrm{O}$ efeito do $\mathrm{Al}$ sobre as diferentes formas do $\mathrm{P}$ pode ser importante para o entendimento dos mecanismos de tolerância da planta ao $\mathrm{Al}$ (Dong et al., 2004; ZHENG et al., 2005). RoRIsON (1965), estudando o efeito do $\mathrm{Al}$ sobre a incorporação de ${ }^{32} \mathrm{P}$ em Onobrychis sativa Lam., demonstrou que este cátion aumentava os teores de $\mathrm{Pi}$, mas reduzia os teores de nucleotídeos e de hexoses-P e a porcentagem de esterificação. Em raízes de cevada, apesar de ter reduzido a incorporação de $\mathrm{P}$ em açúcares fosforilados, o Al aumentou as concentrações de ATP e de outros nucleotídeos trifosfatados e a concentração total de RNA (ClarKSon, 1966). Além de não ter sido encontrado nenhum trabalho recente, visando quantificar o efeito do Al sobre a partição das diferentes formas de $P$, os que existem não são conclusivos justificando novas pesquisas que conduzam a um entendimento mais perfeito do modo de ação do $\mathrm{Al}$ sobre a absorção e o metabolismo de $\mathrm{P}$ em plantas.

Esta pesquisa, portanto, teve como objetivo verificar o efeito do $\mathrm{Al}$ sobre a absorção, o acúmulo e o fracionamento do $\mathrm{P}$ em duas cultivares de sorgo com tolerância diferencial ao Al.

\section{MATERIAL E MÉTODOS}

No trabalho foram utilizadas duas cultivares híbridas de sorgo (Sorghum bicolor L., Moench), sendo uma tolerante (BR006R) e outra sensível (BR007A) ao $\mathrm{Al}$, procedentes da Embrapa Milho e Sorgo (Sete Lagoas, MG, Brasil).

As sementes selecionadas, quanto à uniformidade de tamanho e forma, foram desinfetadas superficialmente com hipoclorito de sódio $0,5 \%$ (v/v) por 15 minutos e, em seguida, lavadas em água corrente e água desmineralizada. As sementes foram colocadas para germinar em rolos de papel germiteste, $\mathrm{pH}$ neutro, imersos em solução nutritiva de CLARK (1975), pH 4,0 com 1/3 de força iônica, sob arejamento (Mendonça et al., 2003).

Nos experimentos foram utilizadas plantas de sete dias de idade, selecionadas quanto à uniformidade de tamanho e forma. Elas foram transferidas, em número de quatro, para vasos de 
plásticos contendo 1,6 L de solução nutritiva de Clark, pH 4,0 e expostas ao $\mathrm{Al}$ nas concentrações de 0 e 150 $\mu \mathrm{M}$, aplicado na forma de $\mathrm{Al}_{2}\left(\mathrm{SO}_{4}\right)_{3}$, durante dez dias. A contribuição relativa das diversas formas do fosfato inorgânico nas soluções nutritivas foi estimada utilizando-se o programa de especiação iônica CHEAQS (VERWEIJ, 2006). O experimento foi realizado em sala de crescimento com temperatura controlada $\left(25 \pm 3{ }^{\circ} \mathrm{C}\right)$, fluxo de radiação fotossinteticamente ativa de $230 \mu \mathrm{mol} \mathrm{m}^{-2} \mathrm{~s}^{-1} \mathrm{e}$ fotoperíodo de 16 horas.

Após o tratamento com $\mathrm{Al}$, as plantas de sorgo foram colhidas e lavadas em água corrente e em água desmineralizada e o comprimento das raízes seminais determinado com auxílio de régua milimetrada. As plantas foram divididas em raízes e parte aérea e o material vegetal seco a $70^{\circ} \mathrm{C}$ em estufa de ventilação forçada até massa constante. Amostras do material vegetal seco foram pulverizadas em moinho elétrico em cápsulas de aço inox, digeridas em mistura nítrico-perclórica $(3: 1 ; \mathrm{v} / \mathrm{v})$ e, nos extratos minerais, foram determinados os teores de $\mathrm{P}$ total (Lindeman, 1958) e de Al pelo método da aluminona (WANG e Wood, 1973).

Amostras do material vegetal fresco foram homogeneizadas em nitrogênio líquido, adicionaramse $2 \mathrm{~mL}$ de $\mathrm{HClO}_{4} 0,2 \mathrm{~N}$ e os homogeneizados foram armazenados a $-15{ }^{\circ} \mathrm{C}$, até posterior análise das frações de P, conforme descrito por Hogue et al. (1970). Para o fracionamento das formas de $\mathrm{P}$ os homogeneizados, após descongelamento, foram centrifugados a $10.000 x g$, por 10 minutos e os sobrenadantes removidos. Os resíduos foram lavados duas vezes com $\mathrm{HClO}_{4} 0,2 \mathrm{~N}$ e os sobrenadantes removidos e combinados, completando-se o volume para $25 \mathrm{~mL}$ com $\mathrm{HClO}_{4} 0,2 \mathrm{~N}$. Nesses extratos foram determinados os teores de $\mathrm{P}$ solúvel total (com digestão nítrico perclórica), $\mathrm{P}$ inorgânico $\left(\mathrm{P}_{\mathrm{i}}\right)$ (sem digestão nítrico-perclórica) e $\mathrm{P}$ orgânico $\left(\mathrm{P}_{\text {org }}\right)$ (por diferença: P solúvel total $-\mathrm{P}_{\mathrm{i}}$ ) pelo método de Lindeman (1958). Os resíduos da extração, após secagem, foram ressuspendidos em $6 \mathrm{~mL}$ da mistura etanol:éter:clorofórmio (2:2:1 - v/v/v), incubados em banho-maria a $50{ }^{\circ} \mathrm{C}$, por uma hora, e centrifugados a $10.000 \mathrm{xg}$, por 10 minutos. Os resíduos foram, novamente, ressuspendidos em $4 \mathrm{~mL}$ de éter frio e centrifugados a $10.000 x g$ por 10 minutos. Os sobrenadantes, recolhidos e combinados, após secagem a $50^{\circ} \mathrm{C}$, foram utilizados para determinação do teor de $\mathrm{P}$ na forma de fosfolipídios $\left(\mathrm{P}_{\mathrm{Lip}}\right)$. Os resíduos foram submetidos à nova extração com $5 \mathrm{~mL}$ de $\mathrm{KOH} 0,5 \mathrm{M}$ a $37^{\circ} \mathrm{C}$ durante 17 horas, centrifugados a $10.000 x g$ por 10 minutos e os sobrenadantes utilizados para determinação do teor de $\mathrm{P}$ na forma de ácidos nucléicos $\left(\mathrm{P}_{\mathrm{RNA}}\right)$. Os resíduos, após secagem a $50^{\circ} \mathrm{C}$, foram submetidos à digestão nítrico-perclórica e no extrato determinado a fração fósforo residual $\left(\mathrm{P}_{\text {res }}\right)$ (Hogue et al., 1970).

A absorção de $\mathrm{P}$ foi medida em plântulas intactas de sete dias de idade, obtidas conforme descrito anteriormente. Oito plântulas, cultivadas em solução nutritiva de Clark, $\mathrm{pH}$ 4,0, foram tratadas com $\mathrm{Al} 0$ ou $150 \mu \mathrm{M}$ durante seis dias. Após este período, as plantas foram transferidas para vasos de $500 \mathrm{~mL}$, as soluções de tratamento renovadas, mas a concentração de $\mathrm{P}$ reduzida para $40 \mu \mathrm{M}$. As plantas permaneceram 24 horas nestas soluções, renovadas a cada 6 horas, para a obtenção do equilíbrio dinâmico (ClaAssen e Barber, 1974). Encerrado este período, após lavagem do sistema radicular com água desmineralizada, as plantas foram transferidas para novos vasos contendo $500 \mathrm{~mL}$ de solução nutritiva de Clark, sem Al e com a concentração de Pi de $40 \mu \mathrm{M}$, contendo $0,080 \mathrm{MBq}$ de ${ }^{32} \mathrm{P}\left(\mathrm{NaH}_{2}{ }^{32} \mathrm{PO}_{4}\right)$, livre de carreador. A partir daí, alíquotas de $1 \mathrm{~mL}$ do meio de cultivo passaram a ser periodicamente coletadas até o esgotamento do Pi da solução nutritiva. A radioatividade das amostras foi determinada, sem adição de coquetel de cintilação, em espectrômetro de cintilação líquida, com as janelas inteiramente abertas. As constantes cinéticas foram estimadas pela aproximação gráfico-matemática sugerida por RuIz (1985) e utilizadas para o preparo das isotermas de absorção.

O delineamento experimental utilizado foi o inteiramente casualizado, segundo esquema fatorial, com três repetições. Os resultados foram submetidos à análise de variância, e as médias comparadas pelo teste de Tukey, a $5 \%$ de probabilidade.

\section{RESULTADOS E DISCUSSÃO}

O Al reduziu o crescimento da raiz seminal e a produção de massa seca de raízes e parte aérea nas duas cultivares de sorgo (Tabela 1). As reduções no crescimento da raiz seminal e na produção de matéria seca da parte aérea causadas pelo Al foram, em média, $31 \%$ e $47 \%$ respectivamente, não tendo as cultivares diferido entre si. Na produção de massa seca de raízes da cultivar sensível, entretanto, houve redução significativamente maior do que na tolerante.

O Al liga-se rápida e preferencialmente ao meristema apical das raízes promovendo intensa redução no alongamento radicular (KocHIAN et al., 2004). Por essa razão, o crescimento da raiz seminal tem sido considerado o melhor parâmetro para discriminação de tolerância de sorgo ao Al (FURLANI e Clark, 1981; Cambraia et al., 1991). 
Tabela 1. Efeito do alumínio sobre o crescimento da raiz seminal e a produção massa seca em duas cultivares de sorgo

\begin{tabular}{lcccc}
\hline \multirow{2}{*}{ Cultivar } & Tratamento & Comprimento Raiz Seminal & Raízes & Massa seca \\
\cline { 3 - 4 } Tolerante & & $\mathrm{cm}$ & $\mathrm{g}-\mathrm{N}-266 \mathrm{Ab}$ & $0,583 \mathrm{Aa}$ \\
& $-\mathrm{Al}$ & $27,7 \mathrm{Aa}$ & $0,152 \mathrm{Ba}$ & $0,303 \mathrm{Ba}$ \\
Sensível & $+\mathrm{Al}$ & $19,2 \mathrm{Bb}$ & $0,332 \mathrm{Aa}$ & $0,540 \mathrm{Aa}$ \\
& $-\mathrm{Al}$ & $34,2 \mathrm{Aa}$ & $0,137 \mathrm{Ba}$ & $0,289 \mathrm{Ba}$ \\
\hline
\end{tabular}

* Médias seguidas da mesma letra maiúscula entre tratamentos para a mesma cultivar e da mesma letra minúscula entre as cultivares para o mesmo tratamento não diferem estatisticamente entre si ao nível de 5\%, pelo teste de Tukey.

Ao contrário do verificado em outras cultivares de sorgo (CAmbraiA et al., 1991) e nas mesmas cultivares utilizadas no presente trabalho (GonçALVES, 1998), contudo, não se observou nesse trabalho diferença significativa entre as cultivares quanto ao comprimento da raiz seminal. A produção de massa seca de raízes considerada, também, importante parâmetro discriminatório de tolerância ao Al (Furlani e Clark, 1981; Cambraia et al., 1991), por outro lado, mostrou o diferencial de tolerância ao $\mathrm{Al}$ entre as duas cultivares estudadas. Diferenças como estas não são incomuns, pois as respostas são influenciadas por vários fatores como tempo de exposição, concentração e fonte de $\mathrm{Al}$, composição e $\mathrm{pH}$ da solução nutritiva, entre outros fatores (CAmbraia et al., 1991).

As plantas-controle da cultivar sensível apresentam maior velocidade de absorção de P que as da tolerante, diferença esta que se ampliou com o aumento da concentração de $\mathrm{P}$ no meio de absorção (Figura 1). Na presença de $\mathrm{Al}$, observou-se redução na absorção de P nas duas cultivares, mas com maior intensidade na cultivar sensível. Na presença de $\mathrm{Al}$, observou-se aumento médio de cerca de 2,5 vezes na constante de Michaelis-Menten $\left(\mathrm{K}_{\mathrm{m}}\right)$ e redução de 18\% na velocidade máxima $\left(\mathrm{V}_{\max }\right)$ de absorção de $\mathrm{P}$ pela cultivar sensível, mas aumento de $23 \%$ no $\mathrm{V}_{\max }$ na cultivar tolerante. O somatório desses dois efeitos do Al sobre o sistema de absorção de $\mathrm{P}$ é evidente na redução das inclinações das isotermas de absorção, especialmente na cultivar sensível.

A absorção de P em plantas é mediada por simportes acoplados ao gradiente de prótons sendo um de alta afinidade $\left(K_{m}\right.$ de 3 a $\left.10 \mu \mathrm{M}\right)$ e outro de baixa afinidade $\left(\mathrm{K}_{\mathrm{m}}\right.$ de 50 a $\left.300 \mu \mathrm{M}\right)\left(\mathrm{S}_{\mathrm{M}} \mathrm{TH}, 2002\right.$; VANCE et al., 2003). Na faixa de concentração estudada (abaixo de $40 \mu \mathrm{M}$ ), portanto, foi avaliado o efeito do Al sobre o transportador de Pi de alta afinidade. Embora, o Al aparentemente aumente a concentração de ATP, conforme sugere CLARKSON (1966), a utilização desse nucleotídeo trifosfatado, no entanto, parece decrescer uma vez que a atividade da $\mathrm{H}^{+}$-ATPase que gera o gradiente de prótons necessário para a absorção ativa de $\mathrm{P}$ é inibida pelo Al (CAmbraia e CALbo, 1980; Ahn et al., 2001).

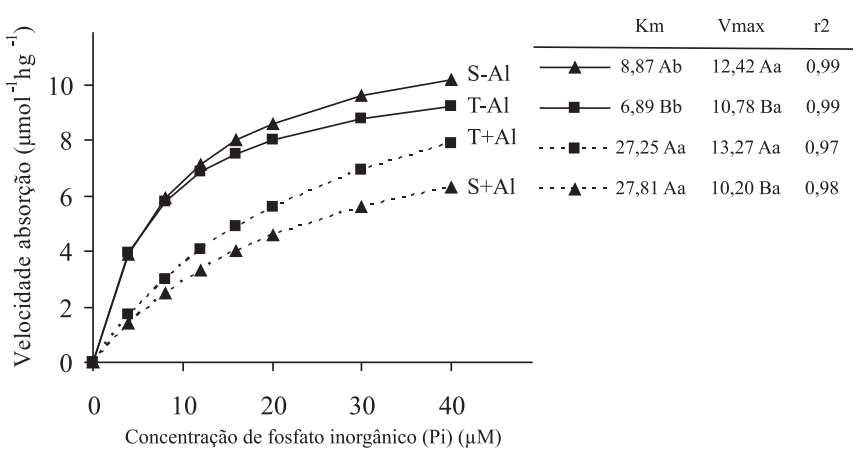

Figura 1. Influência do alumínio sobre a absorção de fosfato inorgânico (Pi) por plantas intactas de duas cultivares de sorgo, uma sensível (S) e outra tolerante (T). A tabela interna mostra os valores de $\mathrm{K}_{\mathrm{m}}, \mathrm{V}_{\max } \mathrm{e}$ coeficiente de correlação $\left(\mathrm{r}^{2}\right)$ para cada condição. Médias seguidas da mesma letra maiúscula entre tratamentos para a mesma cultivar e da mesma letra minúscula entre cultivares para mesmo o tratamento não diferem entre si ao nível de $5 \%$ pelo teste de Tukey.

A presença de Al no meio de absorção, ao contrário do que indicam as análises de $\mathrm{P}$ total nas raízes, reduz a concentração de $\mathrm{P}$ solúvel no apoplasto próximo à membrana plasmática (ZHENG et al., 2005) . Corroborando esse resultado, estima-se que a concentração de $\mathrm{P}$ na forma de $\mathrm{H}_{2} \mathrm{PO}_{4}{ }^{-}$livre na solução de absorção utilizada no presente experimento era de apenas $8 \%$ do $\mathrm{P}$ total. A maior parte do P - $92 \%$ do $\mathrm{P}$ total - estava na forma de diversos pares iônicos com Al. O Al, entretanto, pode afetar diretamente o transportador de Pi modificando as constantes cinéticas de absorção deste íon conforme sugere FAÇANHA e OKOROKOVA-FAÇANHA (2002), confirmando os resultados do presente experimento. 
Os teores de Al aumentaram nas plantas tratadas com este íon apenas no sistema radicular nas duas cultivares (Tabela 2). As cultivares não diferiram entre si, independentemente da parte analisada. Os teores de $\mathrm{Al}$ total, portanto, não indicaram qualquer correlação com a tolerância diferencial manifestada pelas cultivares quanto à produção de massa seca do sistema radicular. Este tipo de resultado tem sido verificado em outros trabalhos com sorgo (CAMBRAIA et al., 1991), milho (CAmbraia e CAMBraiA, 1995) e arroz (Mendonça et al., 2003) e indicam ser o teor total de Al um índice inadequado para a discriminação de plantas quanto à tolerância a este íon.

Os teores de $\mathrm{P}$ total, à semelhança do que ocorreu com os teores de $\mathrm{Al}$, aumentaram no sistema radicular, mas não foram modificados na parte aérea das plantas tratadas com Al (Tabela 2). Na presença de Al, constatou-se na cultivar tolerante teor de $\mathrm{P}$ total significativamente maior que a sensível. Como a produção de massa seca pelas raízes da cultivar tolerante foi menos influenciada do que as do sensível (Tabela 1), aparentemente, a cultivar tolerante pode utilizar parte deste $\mathrm{P}$ para manter o $\mathrm{Al}$ no apoplasto na forma de precipitado. Isto poderia significar um prejuízo para esta cultivar que ficaria privada de parte do P para seu metabolismo foliar. Os teores de P na parte aérea (Tabela 2), contudo, não foram modificados em nenhuma das cultivares, corroborando a hipótese de que o $\mathrm{P}$ poderia estar imobilizando o Al nas raízes reduzindo sua translocação para a parte aérea (ZHENG et al., 2005). No presente experimento, contudo, esta vantagem parece não ter traduzido em redução diferencial no teor de $\mathrm{Al}$ na parte aérea, uma vez que as cultivares não diferiram entre si.

$\mathrm{O}$ tratamento das plantas com $\mathrm{Al}$ resultou em aumento nas duas formas solúveis de $\mathrm{P}\left(\mathrm{P}_{\mathrm{i}}\right.$ e $\left.\mathrm{P}_{\text {org }}\right)$ nas raízes das duas cultivares (Tabela 2 ). Na ausência de $\mathrm{Al}$, a fração de $\mathrm{P}$ solúvel constituía apenas $21 \%$ e $24 \%$ do $\mathrm{P}$ total, mas na presença de $\mathrm{Al}$ passou a constituir $62 \%$ e $48 \%$ do $P$ total, respectivamente, nas cultivares tolerante e sensível. Na parte aérea, ao contrário, observou-se redução nos teores de $\mathrm{P}$ solúvel. Na ausência de $\mathrm{Al}$, esta fração constituía cerca de $70 \%$ e $68 \%$ do $\mathrm{P}$ total, mas na presença de $\mathrm{Al}$ passou a constituir apenas cerca de $53 \%$ e $58 \%$ do $P$, respectivamente, total nas cultivares tolerantes e sensível.

Tabela 2. Teores de Al e frações de P em plantas de duas cultivares de sorgo tratadas com alumínio

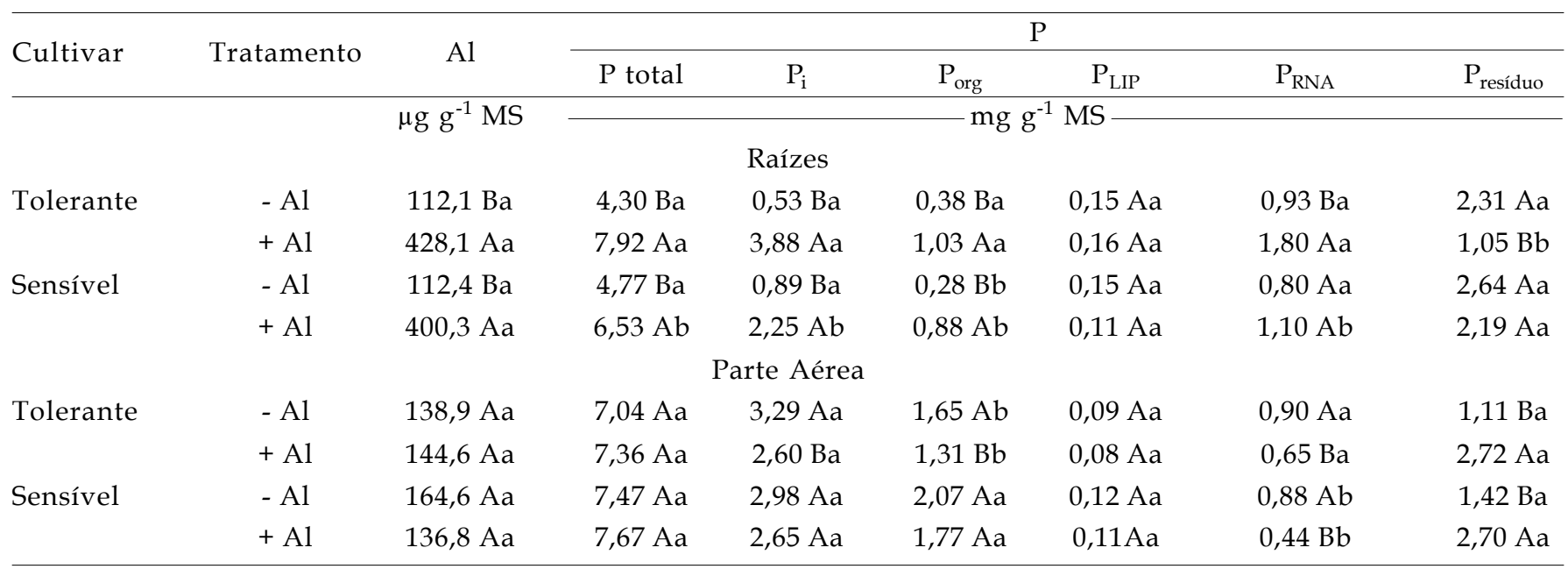

* Médias seguidas da mesma letra maiúscula entre tratamentos para a mesma cultivar e da mesma letra minúscula entre as cultivares para o mesmo tratamento não diferem estatisticamente entre si ao nível de $5 \%$, pelo teste de Tukey.

A fração Pi nas raízes aumentou com o tratamento com $\mathrm{Al}$ nas duas cultivares, principalmente na tolerante (Tabela 2). Como o crescimento das raízes, tanto em termos de comprimento da raiz seminal como de produção de matéria seca (Tabela 1), decresceu com o tratamento com $\mathrm{Al}$, fica evidente que a maior parte deste Pi está no apoplasto e, ou na forma de precipitado e indisponível para as plantas como sugerem diversos trabalhos (CAMBraia e CALBO, 1980; MACKLON et al., 1996). No caso, da cultivar tolerante que acumulou mais $\mathrm{P}_{\mathrm{i}}$ e, também, mais $\mathrm{Al}$ pode ter ocorrido maior precipitação e, conseqüente, redução dos efeitos prejudiciais do $\mathrm{Al}$, conforme sugere ZHENG et al. (2005). Na parte aérea, a fração $P_{i}$ sofreu redução com o tratamento com $\mathrm{Al}$ apenas na cultivar tolerante. Contudo, não resultou em prejuízo significativo no seu crescimento comparativamente à cultivar sensível, indicando que a tolerante pode ser mais eficiente na utilização de $\mathrm{P}$, conforme sugere Mendonça et al. (2003) para arroz. 
O $\mathrm{P}_{\text {org }}$ solúvel aumentou nas raízes das duas cultivares, mas reduziu apenas na parte aérea das plantas da cultivar tolerante tratadas com Al (Tabela 2). A fração $P_{\text {org }}$ é uma fração complexa que pode englobar açúcares, ésteres e outras formas fosforiladas solúveis. Tem sido verificado que o Al inibe a atividade hexocinase, enzima chave na fosforilação de hexoses (CLARKSON, 1966), interferindo com a formação de várias moléculas fosforiladas, incluindo açúcares fosforilados e, até mesmo nos níveis de ATP (PFeffer et al., 1986). A importância desses resultados quanto ao mecanismo de tolerância ao $\mathrm{Al}$, contudo, depende da separação e quantificação das espécies constituintes da fração $P_{\text {org }}$.

A fração $P_{\text {Lip }}$ não foi influenciada pelo tratamento com $\mathrm{Al} \mathrm{em} \mathrm{nenhuma} \mathrm{parte} \mathrm{das} \mathrm{plantas} \mathrm{das}$ duas cultivares (Tabela 2). Esta forma, extraída com solventes orgânicos, representa a porção do $\mathrm{P}$, possivelmente, em lipídios de membrana, e a nãoconstatação de efeito do $\mathrm{Al}$ sobre seu valor sugere não ter o $\mathrm{Al}$ efeito sobre a estrutura da membrana, pelo menos para a duração do tratamento aplicado às plantas neste experimento.

$\mathrm{O}$ tratamento com $\mathrm{Al}$ resultou em aumento do $\mathrm{P}$ na forma de ácidos nucléicos $\left(\mathrm{P}_{\mathrm{RNA}}\right)$ nas raízes apenas na cultivar tolerante, enquanto na parte aérea esta forma de P decresceu nas duas cultivares, especialmente na sensível. GonçaLves et al. (1996), trabalhando com as mesmas cultivares de sorgo, obtiveram resultados semelhantes na parte aérea, enquanto no sistema radicular, o teor de $\mathrm{P}_{\mathrm{RNA}}$ reduziu apenas na cultivar sensível. Esses autores, contudo, além de tratarem as plantas com uma concentração mais elevada de $\mathrm{Al}(185 \mu \mathrm{M})$, utilizaram técnica de extração e de determinação de ácidos nucléicos diferentes da utilizada neste trabalho.

$\mathrm{O}$ teor de $\mathrm{P}$ no resíduo final, constituído provavelmente de peptídeos e proteínas estruturais fosforiladas e $\mathrm{P}_{\mathrm{DNA}}$ (HoGUE et al., 1970), promoveu forte redução nas raízes da cultivar tolerante e aumentou na parte aérea das duas cultivares. É sabido que o Al interage fortemente com os compostos que possuem grupos fosfóricos na sua estrutura, mas a interpretação do efeito do Al sobre estas formas, entretanto, carece de mais estudo, inclusive envolvendo o fracionamento das várias formas desses compostos fosforilados.

\section{CONCLUSÕES}

1. $\mathrm{O} \mathrm{Al}$ absorvido pelas plantas acumula-se predominantemente nas raízes, mas modifica significativamente o metabolismo e o fracionamento do $\mathrm{P}$ tanto nas raízes quanto na parte aérea das plantas das duas cultivares.
2. O Al modifica as constantes cinéticas da absorção de fosfato por raízes de plantas intactas de sorgo, reduzindo a absorção de P nas duas cultivares de sorgo, especialmente na sensível.

\section{AGRADECIMENTOS}

Projeto financiado pelo CNPq e pela FAPEMIG. Os autores agradecem ao $\mathrm{CNPq}$, pela bolsa de produtividade concedida ao segundo autor e à Embrapa Milho e Sorgo, pelo fornecimento das sementes.

\section{REFERÊNCIAS}

AHN, S.J.; SIVAGURU, M.; OSAWA, H.; CHUNG, G.C.; MATSUMOTO, $\mathrm{H}$. Aluminum Inhibits the $\mathrm{H}^{+}$-ATPase activity by permanently altering the plasma membrane surface potentials in squash roots. Plant Physiology, Rockville, v.126, p.1381-1390, 2001.

CAMBRAIA, J.; CALBO, A.G. Efeito do alumínio sobre a absorção e sobre o transporte de fósforo em dois cultivares de sorgo (Sorghum bicolor L. Moench). Revista Ceres, Viçosa, v.27, p.615-625, 1980.

CAMBRAIA, J.; CAMBRAIA, M.C. Avaliação de milho quanto à tolerância ao alumínio, em solução nutritiva. Revista Ceres, Viçosa, v.42, p.297-307, 1995.

CAMBRAIA, J.; SILVA, M.A.; CANO, M.A.O.; SANT'ANNA, R. Método simples para avaliação de cultivares de sorgo quanto a tolerância ao alumínio. Revista Brasileira de Fisiologia Vegetal, Londrina, v.3, p.87-95, 1991.

CLAASSEN, N.; BARBER, S.A. A method for characterizing the relation between nutrient concentration and flux into roots of intact plants. Plant Physiology, Rockville, v.54, p.564$568,1974$.

CLARK, R.B. Characterization of phosphatase of intact maize roots. Journal of Agricultural and Food Chemistry, Washington, v.23, p.458-460, 1975.

CLARKSON, D.T. Effect of aluminum on the uptake and metabolism of phosphorus by barley seedlings. Plant Physiology, Rockville, v.41, p.65-72, 1966.

DONG, D.; PENG, X.; YAN, X. Organic acid exudation induced by phosphorus deficiency and/or aluminum toxicity in two contrasting soybean genotypes. Physiologia Plantarum, Copenhagen, v.122, p.190-199, 2004.

FAÇANHA, A.R.; OKOROKOVA-FAÇANHA, A.L. Inhibition of phosphate uptake in corn roots by aluminum-fluoride complexes. Plant Physiology, Rockville, v.129,p.1763-1772, 2002.

FURLANI, P.R. \& CLARK, R.B. Screening sorghum for aluminum tolerance in nutrient solutions. Agronomy Journal, Madison, v.73, p.587-594, 1981. 
GAUME, A.; MÄCHLER, F.; FROSSARD, E. Aluminum resistance in two cultivars of Zea may L.: root exudation of organic acids and influence of phosphorous nutrition. Plant and Soil, Dordrecht, v.234, p.73-81, 2001.

GONÇALVES, J.F.C.; CAMBRAIA, J.; SANT'ANNA, R.; PACHECO, S. Aluminum and zinc effects on the metabolism of ribonucleic acid in two sorghum cultivars. Revista Brasileira de Fisiologia Vegetal, Londrina, v.8, p.81-86, 1996.

GONÇALVES, J.F.C. Produção de ácidos orgânicos e tolerância de sorgo à toxicidade do alumínio. 1998. 95f. Dissertação (Doutorado em Fisiologia Vegetal) - Universidade Federal de Viçosa, Viçosa, MG.

HOGUE, E.; WILCOX, G.E.; CANTLIFEE, D.J. Effect of soil phosphorus levels on phosphate fractions in tomato leaves. Journal of the American Society for Horticulture Science, Alexandria, v.95, p.174-176, 1970.

KOCHIAN,L.V.;HOEKENGA, O.A.;PIÑEROS, M.A. How docrop plants tolerate acid soils? Mechanisms of aluminum tolerance and phosphorous efficiency. Annual Review of Plant Physiology and Molecular Biology, Palo Alto, v.55, p.459-493, 2004.

LIAO, H.; WAN, H.; SHAFF, J.; WANG, X.; YAN, X.; KOCHIAN, L. Phosphorus and aluminum interactions in soybean in relation to aluminum tolerance. Exudation of specific organic acids from different regions of the intact root system. Plant Physiology, Rockville, v.141, p.674-684, 2006.

LINDEMAN, W. Observations on the behavior of phosphate compounds in Clorella at transition from dark to light. In: UNITED NATIONS INTERNATIONAL CONFERENCE ON THE PEACEFUL USES OF ATOMIC ENERGY, Geneva, v.24, p.8-15, 1958.

MACKLON, A.E.S.; LUMSDON, D.G.;SIM, A; McHARDY, W.J. Phosphate fluxes, compartmentation and vacuolar speciation in root cortex cells of intact Agrotis capillaris seedlings: effect of non-toxic levels of aluminium. Journal of Experimental Botany, London, v.47, p.793-803, 1996.

MENDONÇA, R.J.; CAMBRAIA, J.; OLIVEIRA, J.A.; OLIVA, M.A. Efeito do alumínio na absorção e na utilização de macronutrientes em duas cultivares de arroz. Pesquisa Agropecuária Brasileira, Brasília, v. 8, p.843-848, 2003.

MORIMURA, S.; MATSUMOTO, H. Effect of aluminum on some properties and template activity of purified pea DNA. Plant and Cell Physiology, Kyoto, v.19, p.429-436, 1978.

OLMOS, I.L.; CAMARGO, M.N. Ocorrência de alumínio tóxico nos solos do Brasil, sua caracterização e distribuição. Ciência e Cultura, Campinas, v.28, p.171-180, 1976.

PFEFFER, P.E.; TU, S.I.; GERASIMOWICZ, W.V.; CAVANAUGH, J.R. In vivo ${ }^{31} \mathrm{P}$ NMR studies of corn root tissue and its uptake of toxic metals. Plant Physiology, Rockville, v.80, p.77-84, 1986.

RORISON, I.H. The effect of aluminium on the uptake and incorporation of phosphate by excised sainfoin roots. New Phytologist, Oxford, v.64, p.23-27, 1965.
RUIZ, H. A. Estimativa dos parâmetros cinéticos $\mathrm{K}_{\mathrm{m}}$ e $\mathrm{V}_{\text {max }}$ por uma aproximação gráfico-matemática. Revista Ceres, Viçosa, v.32, p.79-84, 1985.

SMITH, F.W. The phosphate uptake mechanism. Plant and Soil, Dordrecht, v.245, p.105-114, 2002.

VANCE, C.P.; UHDE-STONE, C.; ALLAN, D.L. Phosphorus acquisition and use: critical adaptations by plants for securing a nonrenewable resource. New Phytologist, Oxford, v.157,p.423-447, 2003.

VERWEIJ, W. Chemical Equilibria in Aquatic System (CHEAQS, Pro version 2006.1) - PC calculating program (http:/ /home.tiscali.n1/cheaqs). 2006.

VITORELLO, V.A.; CAPALDI, F.R.; STEFANUTO, V.A. Recent advances in aluminium toxicity and resistance in higher plants. Brazilian Journal of Plant Physiology, Londrina, v.17, p.129143, 2005.

WANG, C.; WOOD, F.A. A modified aluminon reagent for the determination of aluminum after $\mathrm{HNO}_{3}-\mathrm{H}_{2} \mathrm{SO}_{4}$ digestion. Canadian Journal of Soil Science, Ottawa, v.53, p.237-239, 1973.

ZHENG, S.J.; YANG, J.L.; HE, Y.F.; YU, X.H.; ZHANG, L.; YOU, J.F.; SHEN, R.F.; MATSUMOTO, H. Immobilization of aluminum with phosphorus in roots is associated with high aluminum resistance in buckwheat. Plant Physiology, Rockville, v.138,p.297-303, 2005. 